\title{
Numerical Classification of the Tribe Klebsielleae
}

\author{
By SHOSHANA BASCOMB*, S. P. LAPAGE, W. R. WILLCOX \\ AND M. A. CURTIS \\ Computer Trials Department, National Collection of Type Cultures, \\ Central Public Health Laboratory, Colindale Avenue, London N.W. 9
}

(Accepted for publication 3I March I97I)

\begin{abstract}
SUMMARY
A numerical classification study was carried out on 77 strains of Klebsiella and related groups. Three methods of numerical classification were used: median sorting, single linkage cluster analysis and minimum spanning tree. All three contributed to the final decision on the taxa, but yielded substantially the same results. Of the three, the median sorting, if used alone, would have provided the most information.

The validity of the genus Klebsiella was confirmed but the inclusion of the three recognized species of Enterobacter in one genus was not confirmed. The genus Klebsiella was divided into six taxa, one of which is proposed as $K$. mobilis synon. Enterobacter aerogenes. E. cloacae occupied a rank similar to that of the genus $K l e b s i e l l a$, while E. liquefaciens was most closely related to the genus Serratia and it is proposed to include it as S. liquefaciens. Enterobacter 'pigmentés' was found to be closely related to Chromobacterium typhiflavum.
\end{abstract}

\section{INTRODUCTION}

During the development of a scheme for the identification of bacteria by computer (Lapage, Bascomb, Willcox \& Curtis, I970) it was found necessary to divide the Gramnegative rod-shaped bacteria under study into taxa that would differ by at least two characters. The classification of the tribe Klebsielleae (Ewing, 1963) did not lend itself easily to such a treatment as the tribe has been divided differently by several authors.

Cowan, Steel, Shaw \& Duguid (I960) studied I72 Klebsiella strains and proposed a division into six categories, of which Klebsiella aerogenes, $K$. pneumoniae, $K$. ozaenae and $K$. rhinoscleromatis were assigned specific rank, and subspecific rank was assigned to $K$. edwardsii var. atlantae and $K$. edwardsii var. edwardsii. Their study did not include the socalled ' $K$. oxytocum' group, and they agreed with Lautrop (1956) that this group should be removed from Klebsiella.

Slopek \& Durlakowa (1967) studied 85I Klebsiella strains and their grouping was generally in agreement with that of Cowan et al. (1960), though the names and ranks of the groups were different as they placed the two varieties of Klebsiella edwardsii into different species, i.e. $K$. aerogenes var. edwardsii and $K$. pneumoniae var. atlantae. Kaluzewski (1967) studied 82 indole-positive Klebsiella strains and found them to be sufficiently different from $K$. pneumoniae to merit species rank as $K$. oxytoca, and he would include in this species all indole-positive strains of Klebsiella regardless of their ability to liquefy gelatin.

In the most recently published Report (I963) of the International Subcommittee on

* Present address: Department of Biochemistry, Imperial College, Imperial Institute Road, London S.W.7. 
Taxonomy of the Enterobacteriaceae, the Klebsiella group (genus) is divided into four biochemical types (typical, ozaenae, rhinoscleroma and oxytocum), while Enterobacter is divided into three biochemical subgroups A, B and C which are respectively synonymous with Enterobacter cloacae, E. aerogenes and E. liquefaciens. Hafnia and Serratia rank as separate groups (genera).

Wilson \& Miles (1964) included two groups of Klebsiella: $K$. aerogenes, divided into five biochemical varieties (typical, oxytocum, scleroma, ozaenae and Friedländer); and $K$. cloacae, divided into varieties $\mathrm{A}, \mathrm{B}$ and $\mathrm{C}$ which are respectively equivalent to Hormaeche \& Edwards's (1960) Enterobacter cloacae, E. aerogenes and E. liquefaciens. They placed Hafnia and Serratia in separate groups.

On the other hand, Fife, Ewing \& Davis (1965) studied 1758 strains of the tribe Klebsielleae and divided them into the following taxa: Klebsiella pneumoniae, K. ozaenae, $K$. rhinoscleromatis, Enterobacter cloacae, E. aerogenes, E. liquefaciens, E. alvei (equivalent to Hafnia) and two subspecies of Serratia marcescens. Their circumscription of $K$. pneumoniae, which we refer to as $K$. pneumoniae sensu lato, is wider than that of Cowan et al. (I960), referred to as $K$. pneumoniae sensu stricto, and would include strains considered by Cowan et al. (1960) as $K$. aerogenes, $K$. pneumoniae, both varieties of $K$. edwardsii and Lautrop's (1956) K. oxytocum.

In general, disregarding taxonomic rank, the above authors agree that the Klebsiella group contains 'ozaenae' and 'scleroma' groups as two distinctive taxa, but disagree about the division within the 'aerogenes/edwardsii/oxytocum/pneumoniae' complex.

The $\mathbf{I} 77$ strains of Enterobacteriaceae under study did not fall conveniently into any of the above schemes, and a numerical classification was thought necessary, because previously published numerical classifications of Enterobacteriaceae have been either too general (Focht \& Lockhart, 1965; Krieg \& Lockhart, 1966; Goodfellow, 1967) or too specific (Lockhart \& Koenig, I965), and have not included the range of strains studied here.

The numerical classification comprised two stages, calculation of a similarity matrix and cluster analysis. Many different methods have been proposed for cluster analysis starting from a similarity matrix. At present there does not seem to be a generally agreed definition of a cluster which would lead to a single accepted method of clustering. Different methods have been applied to the same data, and the results compared to suggest the deficiencies and relative merit of the methods (Lange, Stenhouse \& Offler, 1965; 't Mannetje, I967); methods have been compared on theoretical grounds (Sokal \& Sneath, I963; Proctor, I966; Gower, 1967), and by applying them to artificially generated data (Lange et al. 1965; Sneath, 1966).

Three methods of cluster analysis were used in the present study, and the approach adopted was to regard the different methods as different ways of exploring the original multidimensional data as represented by the similarity matrix. The final classification was then determined by considering the results of the different cluster analyses bearing in mind the known theoretical properties of the methods. This procedure might be criticized as introducing a subjective element into the objective approach of numerical taxonomy, but at present it does not seem possible to accept uncritically the results of any single classification method.

\section{METHODS}

Organisms. The original designation of the I 77 strains and their sources are listed in Table $\mathrm{I}$ : their reference numbers are shown in Fig. 2. Of these strains, 74 were named reference cultures of the family Enterobacteriaceae, and a representative selection was in- 
cluded of both reference and freshly isolated strains belonging to Klebsiella, Chromobacterium typhiflavum, Enterobacter, Hafnia and Serratia.

Methods of testing. All strains were examined for purity, Gram reaction and ability to grow aerobically on nutrient agar, then subjected to 50 cultural and biochemical tests (Table 2). The test methods largely followed those described by Cowan \& Steel, I965 (the particular method followed when alternatives are given is shown in parentheses): motility

Table I. Strains used and their source*

\begin{tabular}{|c|c|c|c|}
\hline \multirow[b]{2}{*}{ Original designation } & \multirow{2}{*}{$\begin{array}{l}\text { No. of } \\
\text { strains } \\
\text { tested }\end{array}$} & \multicolumn{2}{|c|}{ Source } \\
\hline & & NCTC & Others \\
\hline Chromobacterium typhiflavum & 5 & I & 4 \\
\hline Citrobacter ballerupensis & I & I & - \\
\hline Citrobacter freundii & 2 & 2 & - \\
\hline Edwardsiella tarda & 3 & 3 & - \\
\hline Enterobacter aerogenes & 3 & 3 & - \\
\hline Enterobacter cloacae & 27 & 6 & $2 \mathrm{I}$ \\
\hline Enterobacter liquefaciens & 6 & - & 6 \\
\hline Enterobacter 'pigmentés' $\dagger$ & 4 & - & 4 \\
\hline Enterobacteria & 6 & - & 6 \\
\hline Escherichia adecarboxylata $\dagger$ & I & - & I \\
\hline Escherichia alkalescens & I & $\mathbf{I}$ & - \\
\hline Escherichia coli & 4 & I & 3 \\
\hline Hafnia alvei & I5 & 3 & 12 \\
\hline Klebsiella aerogenes & IO & 5 & 5 \\
\hline Klebsiella edwardsii var. atlantae & 4 & 2 & 2 \\
\hline Klebsiella edwardsii var. edwardsii & 3 & 2 & I \\
\hline Klebsiella oxytocum & 9 & - & 9 \\
\hline Klebsiella ozaenae & 5 & 5 & - \\
\hline Klebsiella pneumoniae & 5 & 5 & - \\
\hline Klebsiella rhinoscleromatis & 5 & 5 & - \\
\hline Klebsiella spp. & 36 & 2 & 34 \\
\hline Kluyvera & $2+$ & - & $\underline{34}$ \\
\hline Salmonella typhimurium & 2 & - & 2 \\
\hline Salmonella typhi & I & I & - \\
\hline Serratia marcescens & 12 & 3 & 9 \\
\hline Shigella boydii & 2 & 2 & - \\
\hline Shigella dysenteriae & I & I & - \\
\hline Shigella flexneri & I & I & - \\
\hline Shigella sonnei & I & I & - \\
\hline Total & 177 & 56 & 119 \\
\hline
\end{tabular}

(method I, but examined 'wet film' preparation); catalase; oxidase; liquefaction of nutrient gelatin; Hugh \& Leifson's oxidation-fermentation test; utilization of citrate (method 2, Simmons); KCN tolerance; oxidation of gluconate (method 2); utilization of malonate; deamination of phenylalanine (i.e. PPA test); urease activity (method I); production of indole (method 2); production of hydrogen sulphide in triple sugar iron media (TSI, method I); production of hydrogen sulphide from nutrient broth (method 3); decarboxylase reactions with arginine, lysine and ornithine (method I); methyl red reaction; VogesProskauer reaction (O'Meara's method); nitrate reduction; presence of $\beta$-galactosidase (ONPG test); production of acid from carbohydrates in peptone water (PWS) with 
Andrade's indicator (final concentration of glucose was $0.6 \%(\mathrm{w} / \mathrm{v})$, other carbohydrates $0.4 \%(\mathrm{w} / \mathrm{v}))$; production of gas from glucose PWS.

Tests and scoring. The tests used are given in Table 2 in three columns, and the methods of coding the test results head the columns. The first column shows the tests in which all the strains gave either a positive or a negative result. These tests were neither used in the calculation of similarities nor coded. The second column gives the tests in which four levels of scoring,,,$+ \pm \mp$, and - , were adopted, and the third column gives those tests that

Table 2. List of tests used and method of coding

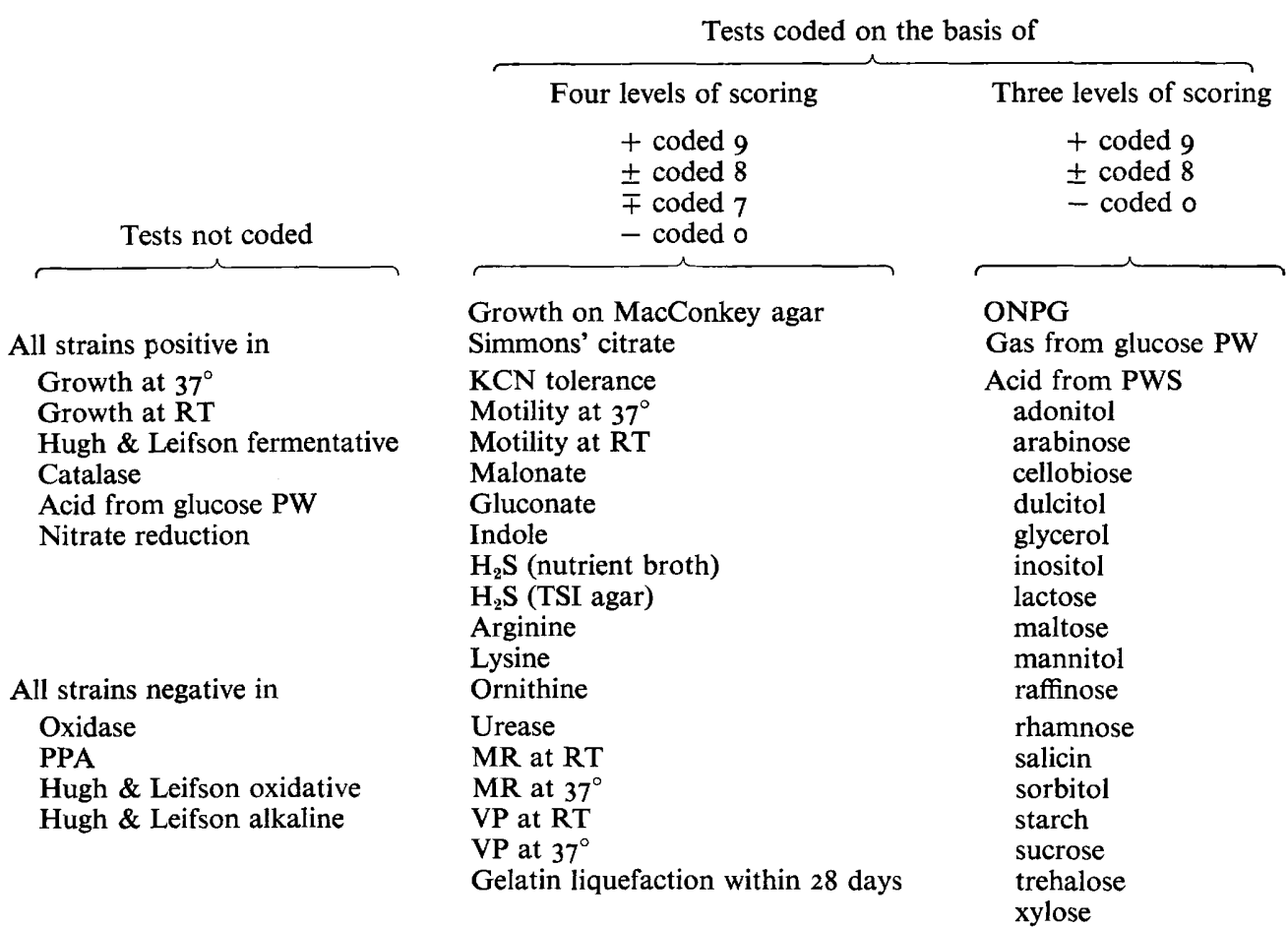

$\mathrm{PW}=$ peptone water; PWS $=$ peptone water plus appropriate sugar; $\mathrm{RT}=$ room temperature or incubator at $22^{\circ}$ or $30^{\circ} ; \mathrm{PPA}=$ deamination of phenylalanine; $\mathrm{MR}=$ methyl red test; VP = Voges-Proskauer test; TSI = triple sugar iron medium.

required only three levels,,+ \pm and - . The same coding was used in both cases, i.e. 9 for ,+ 8 for, \pm 7 for $\mp$ and $o$ for - . A positive result whether strong or weak was thus scored with a high relative value compared with a negative result, as it was considered that a positive reaction, even if weak $( \pm)$ or doubtful $(\mp)$, indicates the presence of the enzyme systems involved while a negative result suggests their absence. The results of two tests, gelatin liquefaction after 5 days and pigment production, were used in the conventional identification but not in the numerical classification.

Calculation of similarities. The similarity between strains $i$ and $j$ in test $t$ is calculated as

$$
S_{t i j}=\mathrm{I}-\frac{\left|r_{t i}-r_{t j}\right|}{R_{t}},
$$

where $r_{t i}$ and $r_{t j}$ are the coded test results and $R_{t}$ is the range of the test, equal to 9 for a test 
coded o to 9. If either $r_{i i}$ or $r_{t j}$ is unknown, $S_{t i j}=0$ and a 'no comparison' is counted. Then the overall similarity, $S_{i j}$, is the average of the similarities for all the individual tests,

$$
S_{i j}=\frac{\mathrm{I}}{N_{i j}} \sum_{t} S_{t i l},
$$

where $N_{i j}$ is the number of comparisons for the pair of strains, i.e. the total number of tests minus the number of no comparisons counted.

This measure is the similarity equivalent of the mean character difference measure of distance (Sokal \& Sneath, I963, p. I46). The measure includes negative matches, and the resulting similarities (Table $3 a$ ) are almost the same as those given by a simple matching coefficient (Sokal \& Sneath, 1963, p. I33) in which \pm and $\mp$ are equated with $+($ Table $3 b$ ). However, the small allowances made for the differences between,+ \pm and $\mp$ results were judged reasonable considering the interpretation of \pm and $\mp$ results for this material.

Table 3. Similarities between two strains in a single test

(a)

Quantitative measure

Result of first strain

$\overbrace{+ \pm \mp \quad-}$

(b)

Matching coefficient

Result of first strain

$\left\{\begin{array}{ccccc}++ & \pm & \mp & - \\ \pm & \text { I } & \text { I } & \text { I } & 0 \\ \mp & \text { I } & \text { I } & \text { I } & 0 \\ - & 0 & \text { I } & \text { I } & 0\end{array}\right.$

Result of second strain

Cluster analysis. The similarity between all pairs of strains was calculated in the computer which then sorted the strains into clusters by three different methods: median sorting (Gower, 1967); single linkage cluster analysis (Sneath, 1957) with levels reducing consecutively by $2.5 \%$; and the minimum spanning tree method (Gower \& Ross, 1969).

The single linkage and minimum spanning tree methods are closely related. The wellknown single linkage cluster analysis usually operates by scanning the similarity matrix for links (similarities above a current threshold clustering level). When a link is found the two objects are clustered or, if they are members of clusters previously formed, the two clusters are coalesced. The threshold clustering level is usually decreased in steps from a high level until all the objects form a single cluster. In single linkage cluster analysis the majority of the similarities in the matrix are redundant since, when two clusters join through a link between a single member of each, the similarities of all the other members of the first cluster with the other members of the second cluster are irrelevant to the continuance of the clustering process.

Gower \& Ross (1969) showed that it is possible to discover, before performing the analysis, just which similarities will be operative in forming the clusters of the single linkage analysis. If there are $n$ objects in the study there are $(n-1)$ of these links and they form the ' minimum spanning tree' connecting all the objects. The usual method of single linkage cluster analysis can now be applied but only the similarities in the minimum spanning tree need to be scanned. In Gower \& Ross's method the similarity matrix of $(n(n-1) / 2)$ entries need not be held in the computer store, therefore their method of single linkage cluster analysis has great computational advantages if large numbers of objects are involved.

However, if the minimum spanning tree itself is available the exact similarities at which objects and clusters combine are known, whereas single linkage cluster analysis gives the 
clusters formed at a series of threshold levels. Fig. I shows how dendrograms derived by single linkage cluster analysis and directly from the minimum spanning tree may differ. In this paper the dendrogram derived directly from the minimum spanning tree is considered to be the result of a minimum spanning tree cluster analysis. Any differences between the two dendrograms can be reduced by using smaller threshold level steps in the single linkage clustering, but if the steps are too small there will be computational difficulties. The two methods were included in the present study to see whether the extra information provided by the minimum spanning tree method was of any significance in the final classification.

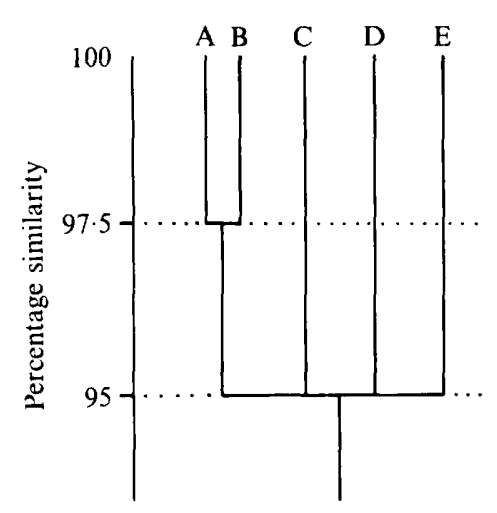

(a)

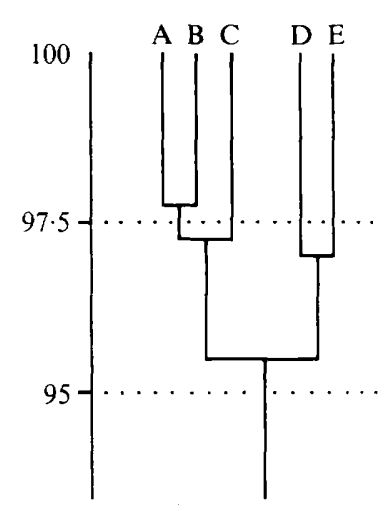

(b)

Fig. 1. Dendrograms derived from the same hypothetical data: $(a)$ by single linkage cluster analysis using steps of $2.5 \% ;(b)$ using exact similarities from the minimum spanning tree.

The median sorting method of cluster analysis is related to the average linkage clustering methods of Sokal \& Michener (1958). The method is most easily explained by a geometrical representation (Gower, 1967 ). Objects are considered as points in a multidimensional space

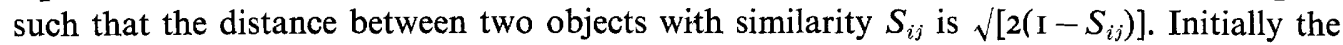
two closest objects (the objects having the highest similarity), say $i$ and $j$, are joined. The cluster $(i j)$ is represented by a single point halfway between $i$ and $j$, and the distances of all other points from the cluster are found on this representation. The distances of other points from $i$ and $j$ individually are not considered further. The smallest distance is again found and the process repeated. Thus a cluster is always represented as a single point, and when two clusters join they are again replaced by a single point halfway between them irrespective of the number of individual objects in each cluster. In similarity terms when two points $i$ and $j$ (which may be objects or clusters) join, the similarity between another point $k$ and the new cluster point $(i j)$ is given by

$$
S_{k, i j}=\frac{1}{2}\left[S_{k i}+S_{k j}+\frac{1}{2}\left(\mathrm{I}-S_{i j}\right)\right]
$$

The program used presented the results of the median sorting as clusters at a number of threshold levels as in the usual form of single linkage cluster analysis.

Sokal \& Sneath (1963, p. 192) have noted that single linkage cluster analysis can produce 'long' clusters in which the extreme members may have much lower similarities than the level at which the cluster forms. On the other hand, the division of the clusters formed is more definite since no two members of different clusters can have a similarity greater than the clustering level. Median sorting and similar methods tend to produce more compact 


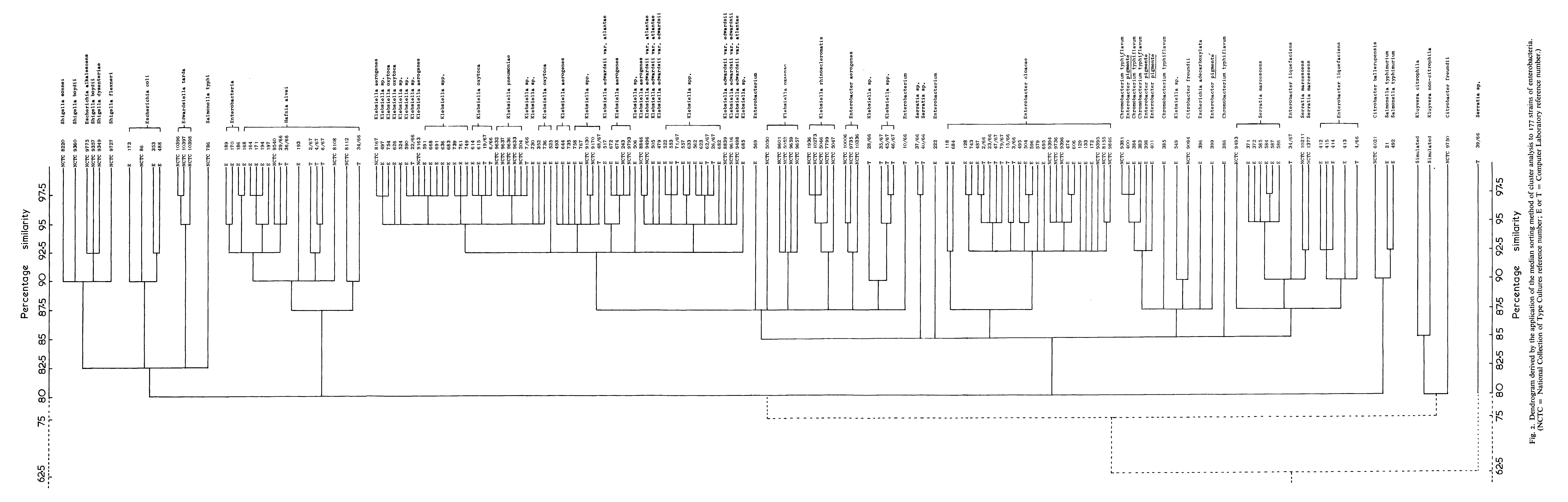


clusters and may give evidence of clusters which do not occur in single linkage cluster analysis. Such clusters may be considered to be acceptable taxa or it may be considered that the continuous spectrum suggested by single linkage cluster analysis is more realistic.

\section{RESULTS}

As a preliminary, conventional identification of all the strains was made in the Computer Laboratory based on the results of the 50 tests and other available information. In the case of collection strains the original names were maintained, whereas the identification of freshly isolated strains was based mainly on the identification tables in Cowan \& Steel (1965). Strains whose test results partially agreed with the definition of a particular species of Klebsiella in the tables were classed as Klebsiella spp. The results of all strains were then subjected to the three clustering methods.

The dendrograms formed by the three methods were in general similar to each other both in the major clusters formed and in the positioning of the majority of the individual strains. Only the dendrogram (Fig. 2) derived by the median sorting method is reproduced in detail since it represents most fully the clusters which were finally chosen after comparison of all three dendrograms. The analysis of this dendrogram is discussed first, followed by an examination of the differences between the median sorting and the other two methods of clustering.

Median sorting. As could be expected (Sneath, 1966), the dendrogram produced by this method is stretched along a wider similarity range than the other two. The level of similarity at which all the strains join is as low as $62.5 \%$. At this level two branches exist, one of a single strain of Serratia, the second of a cluster containing all the remaining strains. This illustrates that a branch at any level may indicate either a single strain or that the computer has formed a cluster at a higher similarity level.

The clusters formed at the $80.0 \%$ level may be equated with the traditional tribes within the Enterobacteriaceae, except that the strains of Hafnia formed a cluster distinct from those of any other tribe. The formation of clusters which might be equated with traditional genera occurs at different levels in these different tribes, and the tribe Klebsielleae appears to be the most homogeneous. Many of the clusters formed at the $87.5 \%$ level can be equated with traditional species, but some clusters include strains belonging to two or more different species, and strains of some species are included in two or more different clusters. The Klebsiella strains of the 'aerogenes/oxytoca/edwardsii/pneumoniae' complex appear as one cluster with a similarity level of $92.5 \%$. Of the Klebsiella clusters formed at the $95.0 \%$ level, that of Klebsiella pneumoniae is the most homogeneous one and the only one which can be equated with a traditional taxon, i.e. Friedländer's bacillus.

Comparison with the other two clustering methods. As can be seen from the simplified versions of the three dendrograms in Fig. $3 a, b$ and $c$, there was overall agreement between the clusters formed by all three methods. However, as can be expected, there were differences first in the similarity levels at which all strains joined and secondly in the number of branches at each level of similarity. The number of branches appearing in each dendrogram at each level of similarity is given in Table 4. The dendrogram formed by median sorting extends over a wider similarity range than the dendrograms formed by the other two methods. The level where all the strains are joined is $62.5 \%$ in the median sorting, $82.5 \%$ in the single linkage cluster analysis and $83.5 \%$ in the minimum spanning tree method. At each level of similarity the largest number of branches is found in the median sorting.

The number of strains included in the important taxa by each of the three methods of cluster analysis, the minimum level of similarity within each cluster and the maximum levels 
Percentage similarity

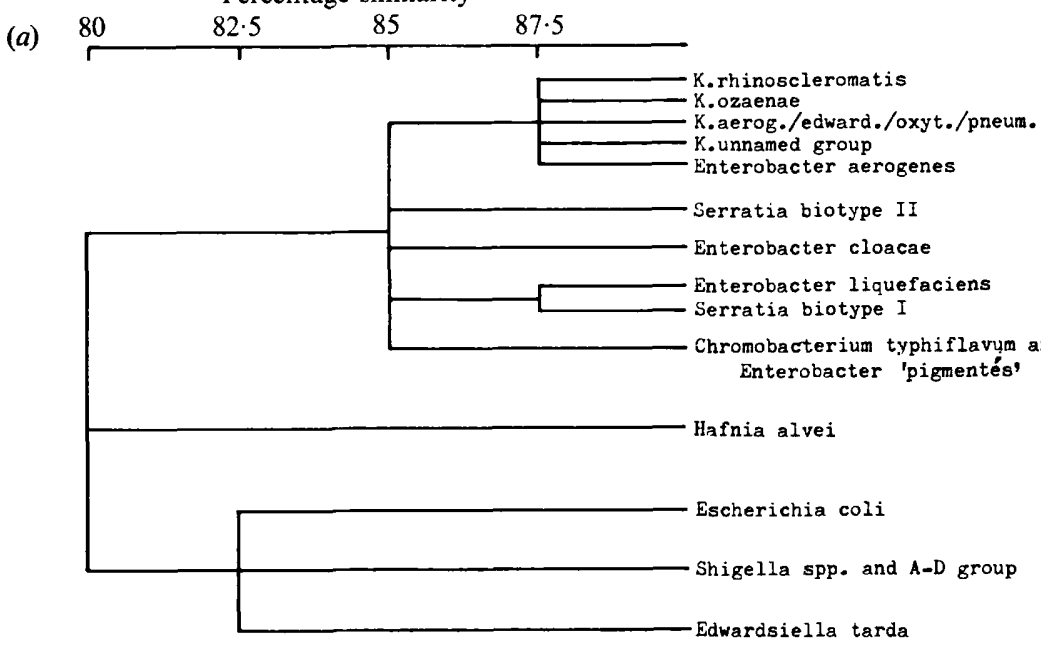

Percentage similarity

(b)

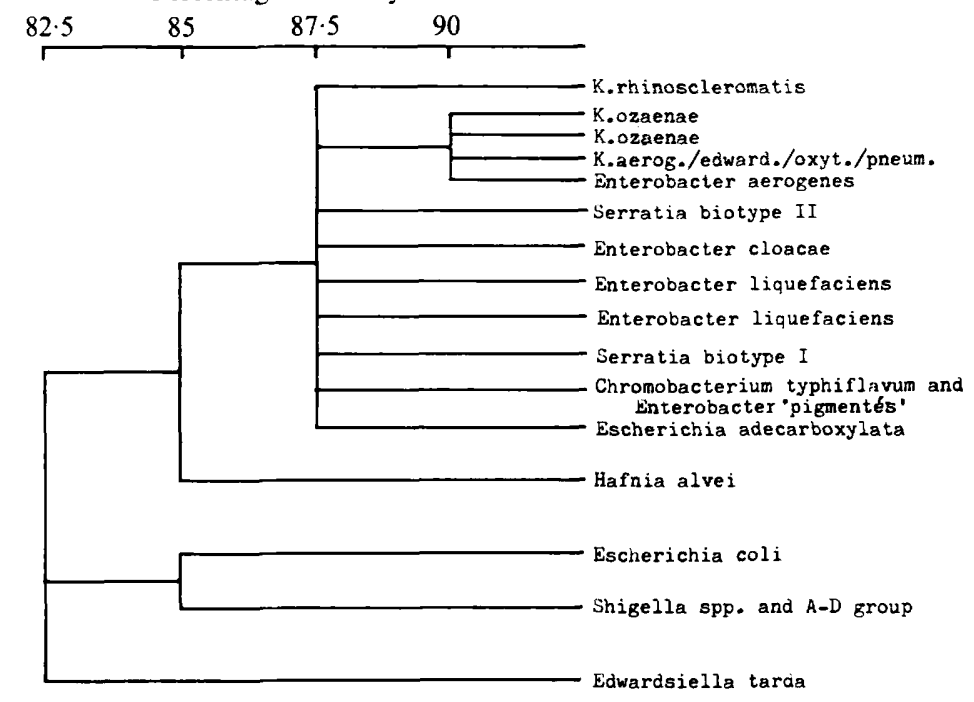

(c)

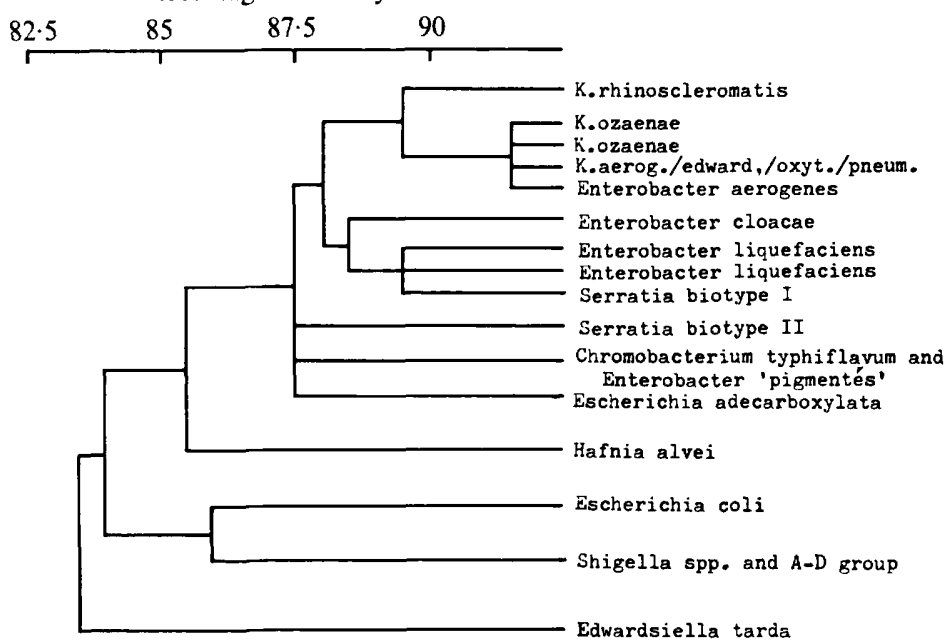

Fig. 3. Schematic form of the dendrograms derived by $(a)$ median sorting, $(b)$ single linkage cluster analysis and $(c)$ the minimum spanning tree method. 
of similarity when joining other clusters are given in Table 5. Most of the definite clusters formed by median sorting were also formed by the other two methods. The level of similarity at which clusters were formed, and at which they joined other clusters, was lower for the median sorting method. The minimum levels of similarity within each cluster and the similarity levels at which clusters join are slightly higher for the minimum spanning tree method than for single linkage cluster analysis because the construction of clusters is continuous in the minimum spanning tree while it proceeds stepwise in levels of $2.5 \%$ in the single linkage. However, the clusters formed by these two methods include a similar number of strains. Though the strains of most taxa were clustered similarly by the three methods, those of Enterobacter liquefaciens, Klebsiella ozaenae, K. pneumoniae (sensu stricto) and of Klebsiella 'unnamed group' were clustered differently.

Table 4. Comparison of the number of branches appearing at each level of similarity in the three different methods of cluster analysis

\begin{tabular}{|c|c|c|c|}
\hline \multirow[b]{2}{*}{$\begin{array}{l}\text { Level of } \\
\text { similarity } \\
(\%)\end{array}$} & \multicolumn{3}{|c|}{ No. of branches by } \\
\hline & $\begin{array}{c}\text { Median } \\
\text { sorting }\end{array}$ & $\begin{array}{l}\text { Single } \\
\text { linkage }\end{array}$ & $\begin{array}{c}\text { Minimum } \\
\text { spanning } \\
\text { tree }\end{array}$ \\
\hline $62 \cdot 5$ & 2 & I & I \\
\hline $75 \cdot 0$ & 3 & $\mathbf{I}$ & I \\
\hline $77 \cdot 5$ & 3 & I & I \\
\hline $80 \cdot 0$ & 7 & I & I \\
\hline $82 \cdot 5$ & IO & 3 & $\mathbf{I}$ \\
\hline 85.0 & 17 & IO & 3 \\
\hline $87 \cdot 5$ & $3 I$ & 25 & 18 \\
\hline $90 \cdot 0$ & 49 & 44 & 25 \\
\hline $92 \cdot 5$ & 83 & 72 & 44 \\
\hline $95 \cdot 0$ & 132 & I I 4 & 76 \\
\hline 97.5 & 177 & I 77 & I 77 \\
\hline 100 & I 77 & 177 & I 77 \\
\hline
\end{tabular}

Final construction of taxa. After comparison of the three dendrograms, taxa were formed mainly on the basis of the clusters existing in the median sorting dendrogram at the similarity level of $87.5 \%$. In the case of Enterobacter cloacae, Hafnia alvei and Klebsiella ozaenae a few more strains were added to those already included in the clusters. Klebsiella pneumoniae (sensu stricto) was treated as a separate taxon, though it does not exist as a separate cluster at this level.

The validity of the taxa thus formed was checked by calculating the mean similarities within and between the taxa (Fig. 4). The mean similarity within a taxon is the average of the similarities between all the pairs that can be formed among the strains of that taxon. The mean similarity between two taxa is the average of the similarities between those pairs obtained by pairing each strain of the first taxon with all the strains of the second taxon. The level of similarity within each taxon was always higher than the level of similarity between taxa. However, the taxa are not of equivalent hierarchical level as the similarities within taxa vary between $99.0 \%$ for Klebsiella pneumoniae (sensu stricto) and $88.7 \%$ for Shigella and the Alkalescens-Dispar group. The highest intertaxa similarity was found between $K$. pneumoniae (sensu stricto) and $K$. pneumoniae (sensu lato) where it was $88.0 \%$. The biochemical characteristics of these taxa are summarized in Table 6, which contains only 40 tests, because the tests in which all the strains gave constant results (Table 2, first column) have been omitted. 


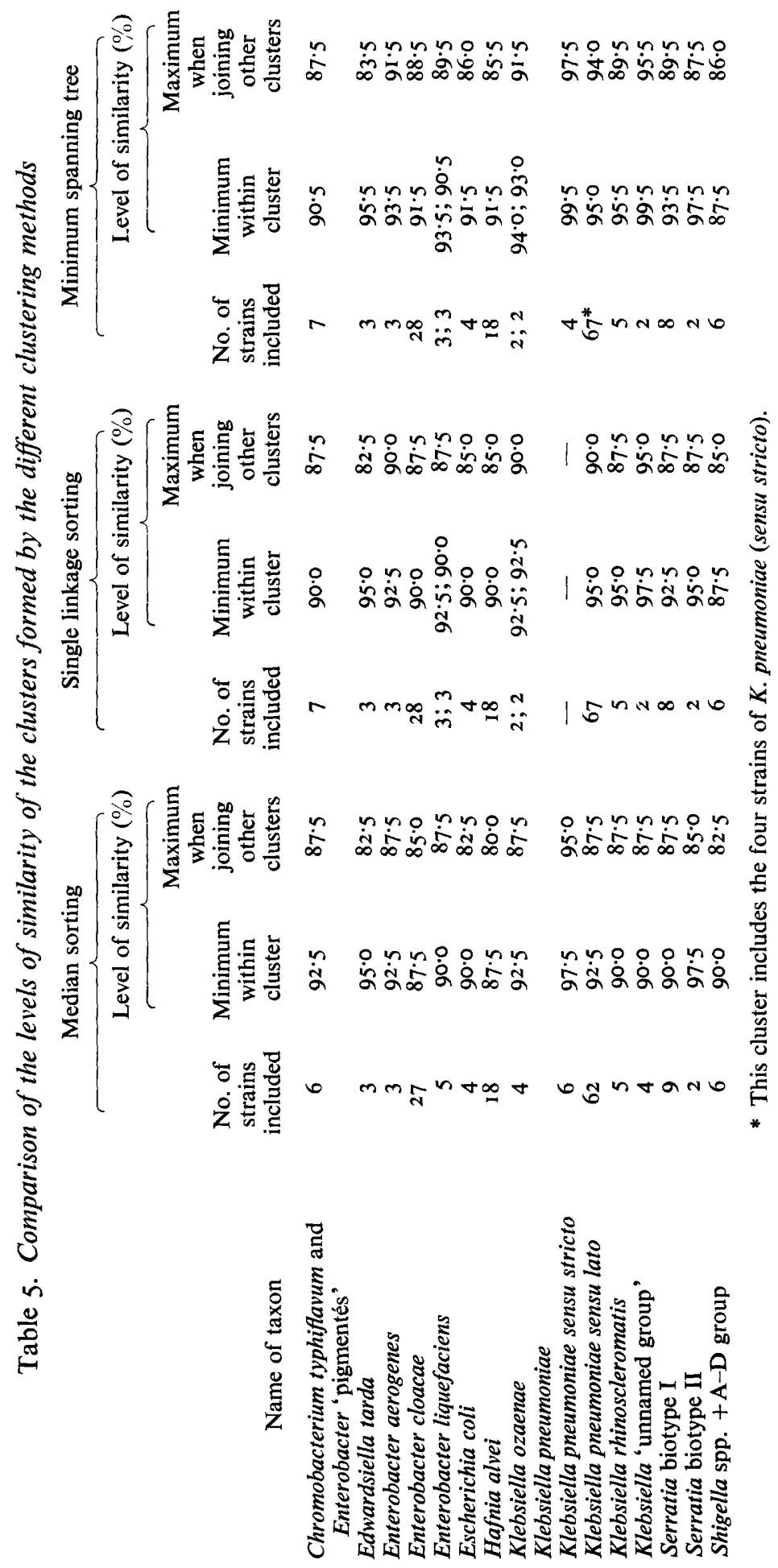




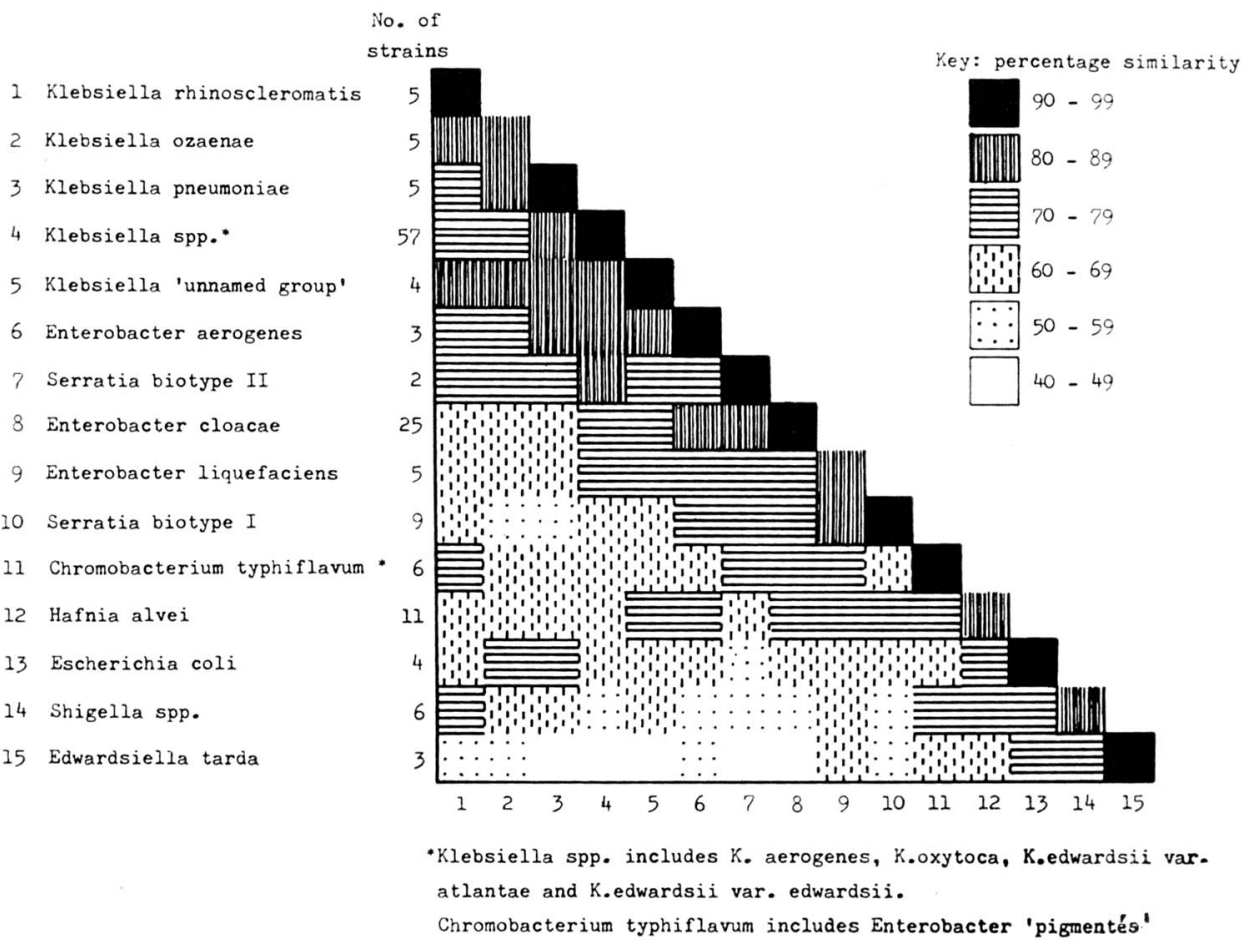

Fig. 4. Mean similarities within and between the taxa formed.

\section{DISCUSSION}

The relationship between the important taxa as revealed by the three different sorting methods is shown in a shortened schematic form in Fig. $3 a, b, c$. In all three the tribe Klebsielleae appears as a separate cluster and includes the following traditional taxa: Enterobacter, Klebsiella, Chromobacterium typhiflavum and Serratia. Similarly, the strains of Hafnia alvei form another separate and distinct taxon with a rank similar to the tribe Klebsielleae. The strains of Escherichia coli, Shigella spp. and the Alkalescens-Dispar group form the third distinct cluster. Strains of Edwardsiella tarda are included in this cluster by median sorting but appear separately from all the other strains in the other two dendrograms. The other strains of Salmonella, Citrobacter, and the two simulated strains of Kluyvera did not form similar discrete groups. However, as very few strains of these taxa were included for comparison in this study no further conclusions are justifiable.

Divisions within the tribe Klebsielleae. In all dendrograms the tribe contains the following separate clusters: Klebsiella, Enterobacter cloacae, and a cluster formed from the strains of Chromobacterium typhiflavum and Enterobacter 'pigmentés'. Two strains of Serratia form a distinct cluster which appears in all dendrograms and is of the same rank as these three clusters. However, the position of strains of E. liquefaciens and of Serratia differ in the three dendrograms.

The Klebsiella cluster contains Klebsiella rhinoscleromatis and Enterobacter aerogenes as separate clusters in all dendrograms, while $K$. ozaenae, though separate from the remaining strains of Klebsiella, appears as one cluster in the median sorting dendrogram and as two in the other dendrograms. 
Table 6. Characteristics of the taxa formed

Tests

Motility $37^{\circ}$

Motility RT

Growth on MacConkey agar

Liquefaction gelatin $\left\{\begin{array}{l}I \text { to } 5 \text { days } \\ 28 \text { days }\end{array}\right.$

Growth on Simmons' citrate

KCN

Gluconate

Malonate

Urease

Indole

$\mathrm{H}_{2} \mathrm{~S}$, TSI

$\mathrm{H}_{2} \mathrm{~S}$, lead acetate paper

Arginine dihydrolase

Lysine decarboxylase

Ornithine decarboxylase

MR $37^{\circ}$

MR RT

VP $37^{\circ}$

VP RT

Gas from glucose

Acid from:

adonitol

arabinose

cellobiose

dulcitol

glycerol

inositol

lactose

(ONPG)

maltose

mannitol

raffinose

rhamnose

salicin

sorbitol

starch

sucrose

trehalose

xylose

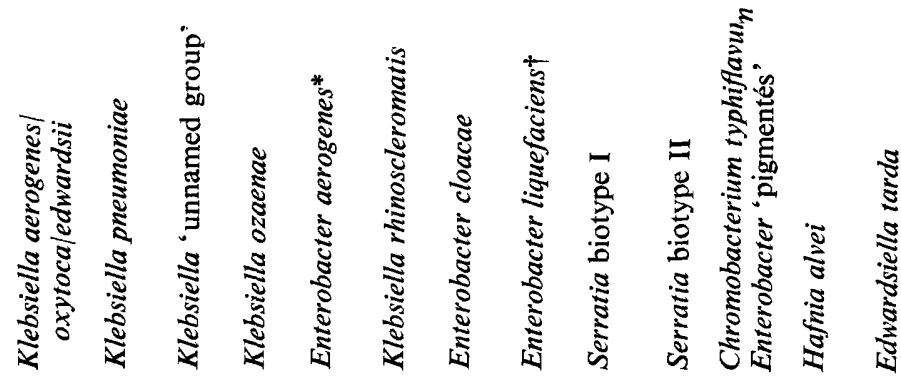

Key: $+=90$ to $100 \%$ of strains yield positive results; $d=I$ I to $89 \%$ of strains yield positive results; $=0$ to $10 \%$ of strains yield positive results.

* Proposed name: Klebsiella mobilis.

$\dagger$ Proposed name: Serratia liquefaciens. 
The strains of Klebsiella aerogenes, $K$. edwardsii, $K$. oxytoca and $K$. pneumoniae (sensu stricto) appear in all three dendrograms as one large cluster. The formation of three of these traditional taxa was based (Cowan et al. 1960) mainly on the reactions to I 3 tests, I I of which were included in our study, while fimbriation and production of gas from lactose at $44^{\circ}$ were not. Moreover, the incubation conditions for the methyl red and Voges-Proskauer tests as well as the method for detecting acetoin were different in the two studies. We found that strains belonging to the traditional taxa gave different results in the methyl red and VogesProskauer tests and in the production of gas from glucose from those expected for these taxa. Our results did not confirm the use of these three tests in the separation of the strains into the traditional species. It is possible that if fimbriation and production of gas from lactose at $44^{\circ}$ had been included in our study the separation would have been different. However, these additions would only have increased the number of tests from 49 to $5 \mathrm{I}$ and these two tests were not necessarily applicable to the differentiation of the other taxa in our study. Attempts to form taxa within this cluster of klebsiellas, either on the basis of traditional classification or on the basis of clusters formed by our numerical techniques, were successful only in the case of $K$. pneumoniae (sensu stricto). All other taxa were not homogeneous enough in their test results and therefore not sufficiently different from each other. It would appear that the strains fall more easily into a continuous spectrum and do not form discrete groups. This is particularly applicable to strains of $K$. oxytoca and $K$. aerogenes. Klebsiella oxytoca differs from $K$. aerogenes in that the former produces indole and liquefies gelatin while the latter is unable to do either. However, strains were found which were similar to $K$. aerogenes yet gave a positive result in one or other, or both of these tests. Hence there does not appear to be a distinction between these two species.

The four freshly isolated strains that formed a distinct cluster in the median sorting dendrogram (Klebsiella 'unnamed group') do not form distinct clusters in the other two. However, the within-group and between-group mean similarity values $(93.6 \%$ and $86.6 \%$ respectively) would lend support to the validity of this taxon. We therefore suggest that the genus Klebsiella should contain the following six taxa:

$$
\text { Klebsiella } \quad \begin{aligned}
\mathrm{I} & =K . \text { aerogenes } / \text { oxytoca/edwardsii } \\
\mathrm{II} & =K . \text { pneumoniae } \\
\mathrm{III} & =K \text { Klebsiella 'unnamed group' } \\
\mathrm{IV} & =K . \text { ozaenae } \\
\mathrm{V} & =\text { Enterobacter aerogenes } \\
\mathrm{VI} & =K . \text { rhinoscleromatis }
\end{aligned}
$$

and postpone the naming of group III until its validity has stood the test of time. We consider that Enterobacter aerogenes should be classified in the genus Klebsiella and propose for this species the name $K$. mobilis nomen novum since the specific epithet 'aerogenes' is already in use for $K$. aerogenes (Kruse) Taylor et al. 1956. Strain CDC 819-56 (NCTC 10006, ATCC I3048), which was included in this study, will thus be the type strain as it is the proposed neotype for Enterobacter aerogenes (Hormaeche \& Edwards, 1960). We regard the name Aerobacter aerogenes (Kruse) Beijerinck 1900 as a nomen dubium as it has been widely used for two different organisms and hence in making our proposal no question of priority with Aerobacter aerogenes arises. A discussion of the confusion caused by the name Aerobacter is given by Carpenter et al. (1970). The characteristics of $K$. mobilis are given in Table 6 and can be compared with those of $K$. aerogenes. 
The validity of the inclusion of Enterobacter aerogenes, $E$. cloacae and E. liquefaciens in the genus Enterobacter is not brought out by our classification. Enterobacter aerogenes was included in Klebsiella in spite of the fact that motility was recorded twice for each strain, i.e. at $37^{\circ}$ and at room temperature. Enterobacter liquefaciens seems to be more related to Serratia biotype I in two of the dendrograms. We therefore propose that $E$. liquefaciens be included in Serratia, which would therefore contain at least the two species $S$. marcescens and $S$. liquefaciens comb.nov. A type strain is not suggested since the type strain for Enterobacter liquefaciens (ATCC I4460, NCIB 932I; Grimes \& Hennerty, I93I), was not included in this study. The characteristics of the taxon are given in Table 6. This proposal is supported by the findings of Hamon, Le Minor \& Peron (1970) that strains of E. liquefaciens and $S$. marcescens show sensitivity to the same bacteriolytic agents. It would also appear that $E$. cloacae is sufficiently distinct from the other two species and might merit genus rank.

The inclusion in Serratia of all red-pigmented Gram-negative rods is also shown to be doubtful, as we could discern at least two biotypes: biotype I which seems to be related to Enterobacter liquefaciens, and biotype II which shows different reaction patterns. The characteristics of these biotypes are given in Table 6. Serratia biotype I resembles $S$. marcescens subsp. marcescens of Fife et al. (1965); it also resembles pattern I of Fulton, Forney \& Leifson (1959) though less closely. The strains of Serratia biotype II differ from the description of Serratia marcescens subsp. kiliensis (Fife et al. 1965), by giving positive results in the Voges-Proskauer test at both $37^{\circ}$ and room temperature, and by producing acid from arabinose and raffinose. Serratia biotype II also differs from pattern 2 of Fulton et al. (1959) in producing urease, and acid from adonitol. Not enough strains of this organism have been studied to discuss its relationship to other described species of Serratia.

Hafnia alvei is sufficiently distinct to be excluded from the tribe Klebsielleae and perhaps should assume a tribe rank on its own, similar to Escherichiaeae and Klebsielleae.

Although in our tests Chromobacterium typhiflavum and Enterobacter 'pigmentés' appear to be the same and to belong to Erwinia herbicola, we have kept the original strain designations throughout this paper because there is no published comparison of the two species, C. typhiflavum and Enterobacter 'pigmentés', although Graham \& Hodgkiss (1967) have shown that $C$. typhiflavus is the same as E. herbicola. The one strain of Escherichia adecarboxylata, also a yellow-pigmented species, included in our study appeared within the Chromobacterium typhiflavum cluster in the median sorting dendrogram but as a separate cluster in the other two. A more detailed study of the yellow-pigmented enterobacteria might show that these three species are closely related to each other and might occupy a genus rank, equivalent to that of Klebsiella.

The computer work was done at Rothamsted Experimental Station, Harpenden, Hertfordshire, using the Orion classification program named CLASP, and we should like to thank Mr J. C. Gower and Mr G. J.S. Ross for their help and advice; and the late Dr K. P. Carpenter of the Dysentery Reference Laboratory, Colindale, for providing reference strains. We also particularly wish to thank Mrs M. Della-Valle and Miss Joyce Stevens for the preparation of the manuscript.

Our thanks are due to the Department of Health and Social Security whose grant for the identification of bacteria using a computer enabled us to carry out this work. 


\section{REFERENCES}

Asal, T., OKumura, S. \& Tsunoda, T. (1957). On the classification of the $\alpha$-ketoglutaric acid-accumulating bacteria in aerobic fermentation. Journal of General and Applied Microbiology, Tokyo 3, 13-33.

BeIJERINCK, M. W. (1900). Schwefelwasserstoffbildung in den Stadtgräben und Aufstellung der Gattung Aërobacter. Zentralblatt für Bakteriologie, Parasitenkunde, Infektionskrankheiten und Hygiene II Abteilung 6, 193-206.

Carpenter, K. P. et al. (1970). Request to the Judicial Commission that Aerobacter Beijerinck 1900 and Aerobacter Hormaeche \& Edwards 1958 be declared rejected generic names. International Journal of Systematic Bacteriology 20, 22 I-224.

CowAN, S. T. \& STEEL, K. J. (I965). Manual for the Identification of Medical Bacteria. Cambridge University Press.

Cowan, S. T., Steel, K. J., Shaw, C. \& Duguid, J. P. (I960). A classification of the Klebsiella group. Journal of General Microbiology 23, 60I-6I 2.

EWING, W. H. (1963). An outline of nomenclature for the family Enterobacteriaceae. International Bulletin of Bacteriological Nomenclature and Taxonomy 13, 95-1 10.

Fife, M. A., EwIng, W. H. \& Davis, R. B. (1965). The Biochemical Reactions of the Tribe Klebsielleae CDC publications, Communicable Disease Center, Atlanta, Georgia.

Focht, D. D. \& Lockhart, W. R. (I965). Numerical survey of some bacterial taxa. Journal of Bacteriology 90, I3I4-I3I9.

Fulton, M., Forney, C. E. \& Leifson, E. (1959). Identification of Serratia occurring in man and animals. Canadian Journal of Microbiology 5, 269-275.

Goodfellow, M. (1967). Numerical taxonomy of some named bacterial cultures. Canadian Journal of Microbiology 13, I365-1 374 .

Gower, J. C. (1967). A comparison of some methods of cluster analysis. Biometrics 23, 623-637.

Gower, J. C. \& Ross, G. J. S. (1969). Minimum spanning trees and single linkage cluster analysis. Applied Statistics 18, 54-64.

GrAHAM, D. C. \& HodGKIss, W. (1967). Identity of Gram-negative, yellow pigmented, fermentative bacteria isolated from plants and animals. Journal of Applied Bacteriology 30, 175-1 89.

Grimes, M. \& HenNerTY, A. J. (193I). A study of bacteria belonging to the subgenus Aerobacter. Scientific Proceedings of the Royal Dublin Society 20, 89-97.

Hamon, Y., Le Minor, L. \& Peron, Y. (1970). Les bactériocines d'Enterobacter liquefaciens. Intérêt taxonomique de leur étude. Compte rendu hebdomadaire des séances de l'Académie des sciences, Paris 270, série D, 886-889.

Hormaeche, E. \& Edwards, P. R. (1960). A proposed genus, Enterobacter. International Bulletin of Bacteriological Nomenclature and Taxonomy ro, 71-74.

KALUZEWSKI, S. (1967). Taxonomic position of indole-positive strains of Klebsiella. Experimental Medicine and Microbiology (formerly Medycyna Doswiadczalna i Mikrobiologia) 19, 350-359.

KREIG, R. E. \& Lockhart, W. R. (I966). Classification of enterobacteria based on overall similarity. Journal of Bacteriology 92, I 275-I280.

LANGe, R. T., Stenhouse, N. S. \& Offler, C. E. (1965). Experimental appraisal of certain procedures for the classification of data. Australian Journal of Biological Sciences 18, I 189-1 205.

Lapage, S. P., Bascomb, S., Willcox, W. R. \& CuRTis, M. A. (1970). Computer identification of bacteria. In Automation, Mechanization and Data Handling in Microbiology, pp. I-22. Edited by A. Baillie \& R. J. Gilbert. Society for Applied Bacteriology Technical Series no. 4.

LAUTROP, H. (1956). Gelatin liquefying Klebsiella strains (Bacterium oxytocum (Flügge)). Acta pathologica et microbiologica scandinavica 39, 375-384.

LeCLerC, H. (1962). Étude biochimique d'Enterobacteriaceae pigmentées. Annales de l'Institut Pasteur, Paris 102, 726-741.

LOCKHART, W. R. \& KoENIG, K. (1965). Use of secondary data in numerical taxonomy of the genus Erwinia. Journal of Bacteriology 90, I638-1644.

Proctor, J. R. (1966), Some processes of numerical taxonomy in terms of distance. Systematic Zoology r5, I 3 I-I 40.

REPORT of the Subcommittee on Taxonomy of the Enterobacteriaceae (1963). International Bulletin of Bacteriological Nomenclature and Taxonomy 13, 69-93. 
Slopek, S. \& Durlakowa, I. (1967). Studies on the taxonomy of Klebsiella bacilli. Archivum Immunologiae et Therapiae Experimentalis $\mathbf{5}, 48 \mathrm{I}-487$.

SNEATH, P. H. A. (1957). The application of computers to taxonomy. Journal of General Microbiology I7, 20I-226.

SNEATH, P. H. A. (1966). A comparison of different clustering methods as applied to randomly spaced points. The Classification Society Bulletin I, 2-18.

SOKAL, R. R. \& MiChEneR, C. D. (1958). A statistical method for evaluating systematic relationships. University of Kansas Science Bulletin 38, 1409-1438.

Sokal, R. R. \& SNeAth, P. H. A. (1963). Principles of Numerical Taxonomy. San Francisco \& London: W. H. Freeman.

Taylor, E. W., Cowan, S. T., Lovell, R., Taylor, J., Thomas, S. B., Cuthbert, W. A., Jacobs, S. E. \& ClEGG, L. F. L. (I956). The nomenclature of the coli-aerogenes bacteria. Journal of Applied Bacteriology I9, 108-III.

'T MANNETJE, L. (1967). A comparison of eight numerical procedures applied to the classification of some African Trifolium taxa based on Rhizobium affinities. Australian Journal of Botany 15, 521-528.

WiLson, G. S. \& Miles, A. A. (1964). Topley and Wilson's Principles of Bacteriology and Immunity, 5th edn. London: Edward Arnold. 